\title{
Spondin2 is a new prognostic biomarker for lung adenocarcinoma
}

\author{
Xiaopeng Yuan ${ }^{1,2, *}$, Tingting Bian ${ }^{1, *}$, Jian Liu ${ }^{3}$, Honggang $\mathrm{Ke}^{4}$, Jia Feng ${ }^{1}$, Qing \\ Zhang $^{1}$, Li Qian ${ }^{1}$, Xiaoli Li ${ }^{1}$, Yifei Liu ${ }^{1}$ and Jianguo Zhang ${ }^{1}$ \\ ${ }^{1}$ Department of Pathology, Affiliated Hospital of Nantong University, Nantong, Jiangsu, P.R. China \\ ${ }^{2}$ Department of Radiation Oncology, Nantong Tumor Hospital, Affiliated Tumor Hospital of Nantong University, Nantong, \\ Jiangsu, P.R. China \\ ${ }^{3}$ Department of Chemotherapy, Affiliated Hospital of Nantong University, Nantong, Jiangsu, P.R. China \\ ${ }^{4}$ Department of Thoracic Surgery, Affiliated Hospital of Nantong University, Nantong, Jiangsu, P.R. China \\ *These authors have contributed equally to this work \\ Correspondence to: Yifei Liv, email: ntdxliuyifei@sina.com \\ Jianguo Zhang, email: $13815212431 @ 163 . c o m$ \\ Keywords: SPON2, pulmonary adenocarcinoma, ADC, prognosis, overall survival \\ Received: February 25, $2017 \quad$ Accepted: June 27, $2017 \quad$ Published: July 26, 2017 \\ Copyright: Yuan et al. This is an open-access article distributed under the terms of the Creative Commons Attribution License 3.0 \\ (CC BY 3.0), which permits unrestricted use, distribution, and reproduction in any medium, provided the original author and source \\ are credited.
}

\section{ABSTRACT}

Spondin 2 (SPON2) is a member of the F-spondin superfamily of genes that encode an extracellular matrix protein. SPON2 has been identified by mRNA differential display screening of cancerous and noncancerous lung cell lines in vitro [1], however, its role in pulmonary adenocarcinoma (ADC) patients remains unclear. In our study, we evaluated whether SPON2 can be used as a biomarker for the diagnosis of pulmonary ADC and any association between SPON2 protein levels and clinicopathological characteristics. Firstly, the mRNA levels of SPON2 in pulmonary ADCs and normal adjacent tissue samples were detected by quantitative reverse transcription polymerase chain reaction ( $q R T-P C R)(n=60)$ assay and the expression of SPON 2 protein were detected by tissue microarray immunohistochemistry analysis (TMA-IHC) $(n=280)$. Overexpression of SPON2 protein in cancerous tissues was associated with the clinical characteristics of ADC patients and their overall survival. Levels of SPON 2 mRNA and protein were significantly expressed higher in ADC tissues than in adjacent normal tissues. Finally, through univariate and multivariate regression analysis, we found that overexpression of SPON2 protein levels correlates with differentiation, positive lymph nodes metastasis, higher serum carcinoembryonic antigen (CEA) level and poor overall survival. Overexpression of SPON2 protein is an independent prognostic biomarker in ADC patients. Our data revealed that SPON2 played an oncogene role in ADC development and progression. Inhibiting SPON2 might represent a new strategy for pulmonary ADC.

\section{INTRODUCTION}

Lung cancer is still the main cause of cancer deaths worldwide ${ }^{[2]}$. Approximately $80-85 \%$ of lung cancers are non-small cell lung cancers (NSCLCs), including squamous cell carcinoma, adenocarcinoma (ADC), large-cell carcinoma and undifferentiated tumors $[2,3]$. All approved remedies for pulmonary ADC are under the condition that adequate targets are detected. Because of the lack of obvious signs and symptoms in the early stages of the disease, it is difficult to make an early diagnosis; therefore, most pulmonary ADC patients miss any opportunity for radical surgery. In addition, without enough available tissue, it can be difficult to reach a diagnosis and preserve sufficient tissue for molecular testing [4]. Survival of pulmonary ADC patients could be 
significantly increased with early detection of the disease; therefore, new biomarkers for early diagnosis, prognosis monitoring, and new therapeutic targets are critically needed.

SPON2 (Spondin 2, Mindin, DIL-1) is the human homologue of the zebrafish genes Mindin1 and Mindin2, which belong to the F-spondin superfamily of secreted extracellular matrix proteins [5-7]. It has been reported that SPON2 is more highly expressed in prostate, ovarian, and colorectal tumors than in adjacent normal tissues $[6,8-10]$. In addition, SPON2 is used as a diagnostic biomarker for prostate and ovarian cancers through its detection in the patient's blood $[6,8]$. Recent research has suggested that SPON2 mediates metastasis-associated in colon cancer 1 (MACC1)-induced colorectal cancer proliferation, invasion, and metastasis in vitro and in vivo, while aberrant overexpression of SPON2 increases adverse disease-free survival in clinical samples [9]. Another study showed that SPON2 is differentially expressed in cancerous and non-cancerous lung cell lines in vitro [1], however its potential role in the progression, metastasis, and patient prognosis of pulmonary ADC remains unclear.

In our study, we determined SPON2 mRNA expression by quantitative reverse transcription polymerase chain reaction (qRT-PCR) assay and its protein expression by tissue microarray immunohistochemistry analysis (TMA-IHC) in pulmonary ADC tissue samples, and correlated the results with the patients' clinical features and overall survival rate. Meanwhile, serum SPON2 concentrations in pulmonary ADC patients were determined by enzyme-linked immunosorbent assay (ELISA). The diagnostic performances were compared to carcinoembryonic antigen (CEA) expression using logistic regression analysis.

\section{RESULTS}

\section{SPON2 expression levels were significantly higher in pulmonary ADC tissues than in normal adjacent tissues}

To detect the difference in SPON2 gene expression between pulmonary ADC tissues and normal adjacent tissues, 60 fresh-frozen tissue samples were collected, comprising 30 cancerous tissue samples and 30 matched normal adjacent tissues. SPON2 mRNA levels were detected by real time-PCR assay. Relative SPON2 mRNA expression levels were normalized to the expression of housekeeping gene GAPDH. There was significantly higher mRNA encoding SPON2 expressed in cancerous tissues $(0.307 \pm 0.017)$ than in the normal adjacent tissues $(0.173 \pm$ $0.006)(\mathrm{p}<.001)$ (Figure 1). Tissue TMA-IHC assay showed a strong correlation between the SPON2 gene and protein expression, SPON2 protein was expressed higher on ADC epithelial cell membranes (Figure 2C1-D1, 2C2-D2) than on normal lung tissues (Figure 2A1-B1, 2A2-B2).

\section{Correlation between SPON2 expression and pulmonary ADC clinicopathological characteristics}

To investigate the role that SPON2 plays in pulmonary ADC pathogenesis, we correlated SPON2 protein expression with the clinicopathological characteristics of ADC patients. A high SPON2 protein expression was significantly associated with differentiation $(P<.01)$, positive lymph node metastasis $(P=.023)$, clinical stage (pTNM stage III-IV, $P=.038$ ), and pattern (lepidic, acinar, papillary, micropapillary, and solid; $P$ $<.01)$ (Table 1).

\section{SPON2 protein overexpression predicts poor overall survival in pulmonary ADC patients}

To analyze the prognostic factors in ADC patients, univariate Cox Regression analysis was administrated to assess the contribution of various potential prognostic factors to survival. Our results showed that the following prognostic markers were associated with poor overall survival: differentiation (hazard ratio [HR], 0.743; 95\% confidence interval $[\mathrm{CI}]: 0.578-0.955 ; \mathrm{P}=.020)$, lymph node metastasis (HR, 0.358; 95\%CI: 0.198-0.648; P $=.001$ ), clinical stage (pTNM stage III-IV; HR, 1.170; 95\%CI: 0.921-1.486; $\mathrm{P}=.032$ ), pattern (HR, 1.143; 95\%CI: $0.986-1.325 ; \mathrm{P}=.026)$, and higher SPON2 expression (HR, 1.583; 95\%CI: 1.035-2.421; $\mathrm{P}=.034$ ) (Table 2). Similar results were shown by the KaplanMeier survival curve analysis (log rank, Chi-squared $=60.24, \mathrm{P}<.001$, Figure $3 \mathrm{~A}$ ), indicating that a higher SPON2 expression predicts poor overall survival in pulmonary ADC patients.

To further study the independent prognostic factors in ADC patients, the results of multivariate analysis showed that differentiation (HR, 0.802; 95\%CI: $0.647-$ 0.994; $\mathrm{P}=.044$ ), positive lymph node metastasis (HR, 0.512; 95\%CI: 0.358-0.732; $\mathrm{P}<.001)$, clinical stage (pTNM stage III-IV; HR, 1.433; 95\%CI: 0.943-2.177; $\mathrm{P}<.001$ ), higher SPON2 expression (HR, 1.626; 95\% CI: 1.063-2.486; $\mathrm{P}=.025$ ) (Table 3) were independent prognostic indicators for overall patient survival. As is known, clinical stage comprises tumor size, lymph node, and organ metastasis, and most ADC patients with organ metastasis diagnosed by chest computerized tomography (CT) scan, positron emission tomography (PET)/CT, and fiber bronchoscope have usually missed the opportunity for surgery, and the data on the clinical stage might be influenced by this; therefore, the clinical stage factor was not discussed in subsequent studies. Kaplan-Meier survival analysis was used to calculate the SPON2 expression level, differentiation, and positive lymph node metastasis to correlate these with patient survival time (Figure 3). Taken together, it was concluded that higher SPON2 protein expression, positive lymph node 
metastasis, and poor differentiation were significantly associated with poor overall survival $(\mathrm{P}<.001)$.

\section{SPON2 levels are helpful in the diagnosis of pulmonary ADC}

Using the results of previous data, SPON2 can be detected in pulmonary ADC tissues by TMA-IHC or qRT-PCR assay. It is known that SPON2 is one kind of extracellular matrix proteins and can be secreted in some tumors, such as prostate cancer, colorectal cancer and ovarian cancer $[6,8,10]$. Whether higher serum SPON2 could help with an earlier diagnosis of pulmonary ADC is still unclear, but it would be more convenient and helpful if SPON2 protein could be detected in patient serum samples. Serum CEA is a commonly used biomarker for NSCLC in clinical diagnosis [11-14]. In our study, the accuracy of serum SPON2 detection was compared to that of serum CEA in a correlation analysis. Serum samples collected from 65 ADC patients and 20 healthy individuals were assessed using ELISA. Distribution of serum CEA and SPON2 in healthy individuals and ADC patients are graphically displayed in Figure 4A-4B, and ROC curves for CEA and SPON 2 are graphically displayed in Figure 4C. ROC analysis showed that CEA had a greater ability to identify ADC samples from healthy controls $(p<0.01)$. Its overall area under the curve (AUC) was 0.932 when healthy controls were included. Excitingly, compared with
CEA detection, SPON2 also showed strong diagnostic performance by the new markers when various stages of ADC samples were used, with an AUC of 0.864 when healthy individuals were performed as controls $(\mathrm{p}<0.01$, Figure $4 \mathrm{C})$, but there is no significant statistical significance compared to CEA and SPON2 $(p=0.14)$.

\section{DISCUSSION}

SPON2, a secreted extracellular matrix protein belonging to the F-spondin superfamily, plays multifaceted roles in tumorigenesis and cancer progression [1, 6, 8, 15]. It is more highly expressed in prostate [16], ovarian [6], colorectal $[9,10,17]$, and gastric cancer [18] compared with that in matched normal adjacent tissues. In lung cancer cell lines, SPON2 was found to be overexpressed compared with that in normal lung cell lines in vitro [1]. However, the role of in pulmonary ADC patients is still unclear. In this study, we evaluated a new biomarker, SPON2, for several performance characteristics related to its potential application in the diagnosis and early detection of pulmonary ADC. SPON2 mRNA transcriptional activity and protein expression were significantly higher in pulmonary ADC tissues than in normal adjacent tissues. All evidence indicates that SPON2 is an oncogene and might be a prognostic biomarker in various cancers, such as ovarian, colorectal, prostate cancer and lung ADC. In addition, the impact of SPON2 on tumor progression,

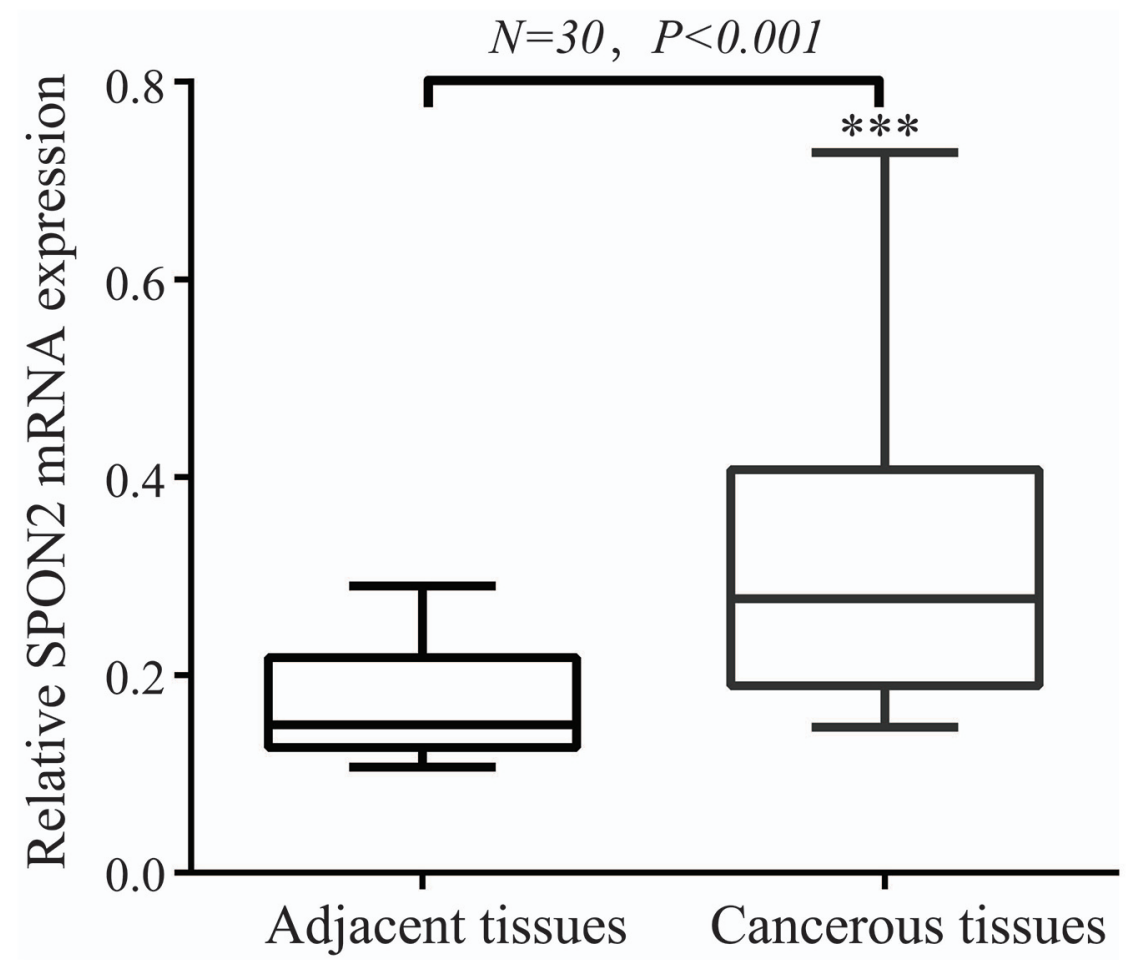

Figure 1: SPON2 mRNA level was significantly higher in pulmonary ADCs tissues than in adjacent normal tissues. SPON2 mRNA was determined by qRT-PCR and relative quantification analysis by normalizing to GAPDH mRNA. 
Table 1: Correlation of SPON2 protein expression with pulmonary ADC patients' clinicopathological characteristics

\begin{tabular}{|c|c|c|c|c|c|}
\hline \multirow[t]{2}{*}{ Variable } & \multirow[t]{2}{*}{ Overall } & \multicolumn{2}{|c|}{ SPON2 expression } & \multirow[t]{2}{*}{$\chi^{2}$} & \multirow[t]{2}{*}{$P$ value } \\
\hline & & Low & High & & \\
\hline \multicolumn{6}{|l|}{ Gender } \\
\hline Male & 153 & 35 & 118 & \multirow[t]{2}{*}{2.630} & \multirow[t]{2}{*}{0.105} \\
\hline Female & 127 & 40 & 87 & & \\
\hline \multicolumn{6}{|l|}{ Age(years) } \\
\hline$\leq 60$ & 141 & 42 & 99 & \multirow[t]{2}{*}{1.305} & \multirow[t]{2}{*}{0.253} \\
\hline$>60$ & 139 & 33 & 106 & & \\
\hline \multicolumn{6}{|l|}{ Smoking } \\
\hline Yes & 65 & 15 & 50 & \multirow[t]{2}{*}{0.594} & \multirow[t]{2}{*}{0.441} \\
\hline No & 215 & 50 & 155 & & \\
\hline \multicolumn{6}{|l|}{ Differentiation } \\
\hline Well & 52 & 15 & 37 & \multirow{3}{*}{22.042} & \multirow{3}{*}{$<0.01 *$} \\
\hline Moderate & 179 & 94 & 85 & & \\
\hline Poorly & 49 & 37 & 12 & & \\
\hline \multicolumn{6}{|l|}{ Tumor size $(\mathrm{cm})$} \\
\hline$\leq 3$ & 147 & 44 & 103 & \multirow[t]{2}{*}{1.562} & \multirow[t]{2}{*}{0.211} \\
\hline$>3$ & 133 & 31 & 102 & & \\
\hline \multicolumn{6}{|l|}{ Lymph node } \\
\hline Positive & 167 & 53 & 114 & \multirow[t]{2}{*}{5.172} & \multirow[t]{2}{*}{$0.023 *$} \\
\hline Negative & 113 & 22 & 91 & & \\
\hline \multicolumn{6}{|l|}{ Clinical stage } \\
\hline Stage I-II & 219 & 65 & 154 & \multirow[t]{2}{*}{4.295} & \multirow[t]{2}{*}{$0.038 *$} \\
\hline Stage III-IV & 61 & 10 & 51 & & \\
\hline \multicolumn{6}{|l|}{ Pathological type } \\
\hline Lepidic & 42 & 22 & 20 & \multirow{5}{*}{36.108} & \multirow{5}{*}{$<0.01^{*}$} \\
\hline Acinar & 92 & 35 & 57 & & \\
\hline Papillary & 62 & 6 & 56 & & \\
\hline Micropapillary & 46 & 8 & 38 & & \\
\hline Solid & 38 & 4 & 34 & & \\
\hline
\end{tabular}

$* \mathrm{P}<0.05$ indicates a significant association among the variables.

metastasis, differentiation, and patterns and its use as biomarker for prognosis linked to pulmonary ADC patient survival is not yet clear.

In order to investigate the correlation of SPON2 overexpression and survival of pulmonary ADC, in our study, high SPON2 protein levels were found to be associated with poor differentiation, positive lymph node metastasis and clinical stage by both univariate and multivariate analysis. Because ADC patients with organ metastasis often lost the opportunity for surgery, the patient survival fraction might have been influenced by the clinical stage in our study; therefore, we excluded the clinical stage factors in the multivariate analysis. We found that differentiation, lymph node metastasis and SPON2 expression played independent roles in pulmonary ADC. Meanwhile, higher SPON2 expression, poor differentiation, and positive lymph node metastasis predict a poor prognosis in pulmonary ADC patients. It also has been confirmed that SPON2 overexpression predicts poor 
Table 2: Prognostic markers for overall survival in ADCs patients by univariate Cox regression analysis

\begin{tabular}{lcccc}
\hline Characteristics & Hazard ratio & \multicolumn{2}{c}{$\mathbf{9 5 . 0 \%}$ confidence interval } & \multirow{2}{*}{ P value } \\
\cline { 3 - 4 } & & Upper & Lower & \\
\hline Sex & 0.738 & 0.52 & 1.048 & 0.089 \\
Age & 1.008 & 0.985 & 1.032 & 0.486 \\
Smoking & 0.947 & 0.551 & 1.627 & 0.843 \\
Differentiation & 0.743 & 0.578 & 0.955 & $0.020^{*}$ \\
Tumor size & 1.057 & 0.899 & 1.243 & 0.501 \\
Lymph node & 0.358 & 0.198 & 0.648 & $0.001^{*}$ \\
Clinical stage & 1.170 & 0.921 & 1.486 & $0.032^{*}$ \\
Pathological pattern & 1.143 & 0.986 & 1.325 & $0.026^{*}$ \\
SPON2 expression & 1.583 & 1.035 & 2.421 & $0.034^{*}$ \\
\hline
\end{tabular}

$* \mathrm{P}<0.05$.

Table 3: Survival curves of pulmonary ADCs patients by the Kaplan-Meier method and the log-rank test

\begin{tabular}{lcccc}
\hline Characteristics & Hazard ratio & \multicolumn{2}{c}{$\mathbf{9 5 . 0 \%}$ confidence interval } & \multirow{2}{*}{ P value } \\
\cline { 3 - 4 } & & Upper & Lower & \\
\hline Differentiation & 0.802 & 0.647 & 0.994 & $0.044^{*}$ \\
Lymph node & 0.512 & 0.358 & 0.732 & $<0.001^{*}$ \\
Clinical stage & 1.433 & 0.943 & 2.177 & $<0.001^{*}$ \\
SPON2 expression & 1.626 & 1.063 & 2.486 & $0.025^{*}$ \\
\hline
\end{tabular}

$* \mathrm{P}<0.05$.
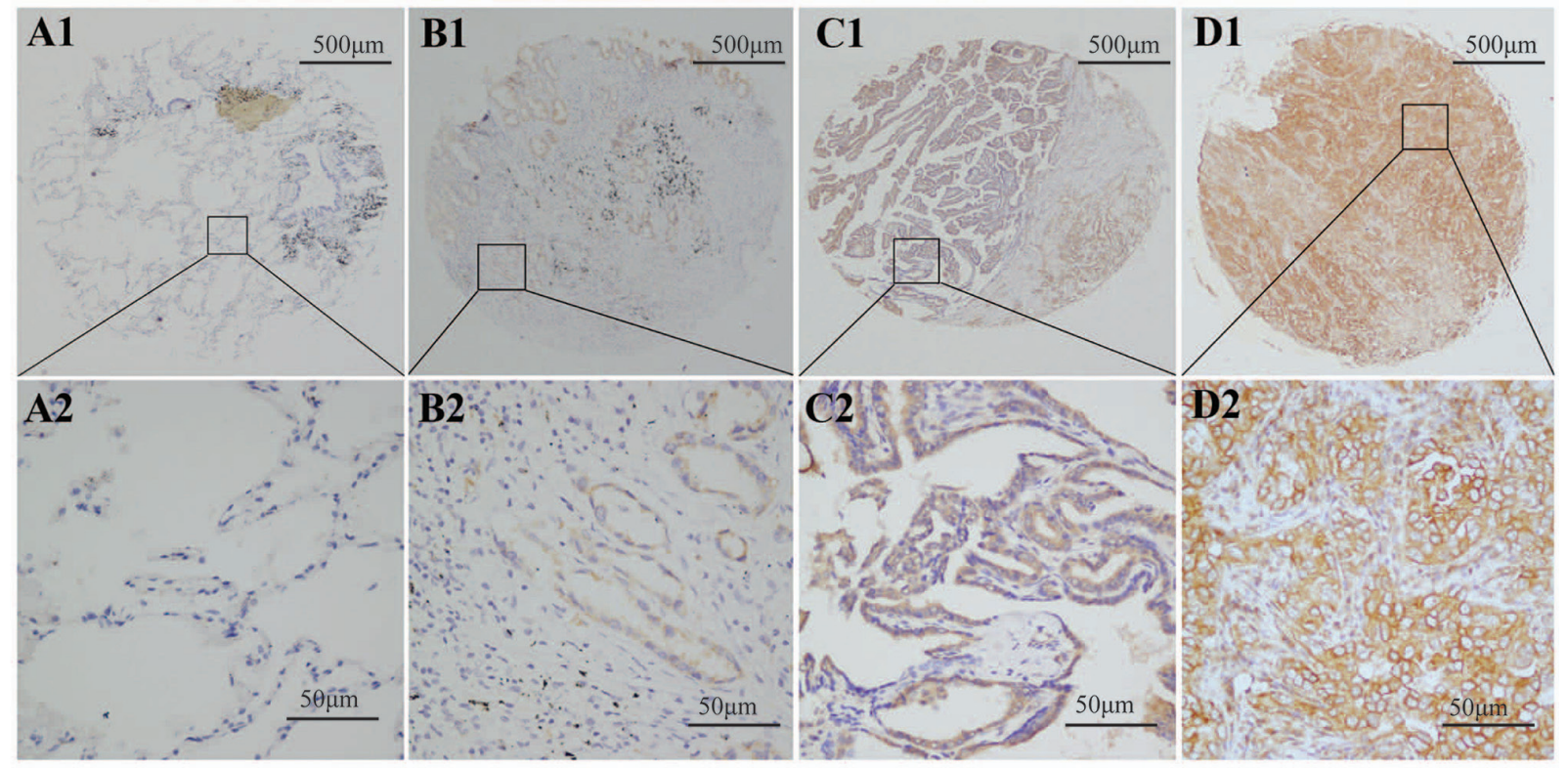

Figure 2: SPON2 protein was detected in pulmonary ADCs tissues and normal lung tissues. SPON2 protein was determined by TMA-IHC. (A1-A2) normal lung tissues, negative for SPON2 protein expression; (B1-B2) pulmonary ADCs tissues, weak positive for SPON2 protein expression; (C1-C2) pulmonary ADCs tissues, moderate positive for SPON2 protein expression; (D1-D2) pulmonary ADCs tissues, strong positive for SPON2 protein expression. A1, B1, C1 and D1 are $\times 40$ magnification $($ bar $=500 \mu \mathrm{m}), \mathrm{A} 2, \mathrm{~B} 2, \mathrm{C} 2$ and D2 are $\times 400$ magnification $($ bar $=50 \mu \mathrm{m}$ ). SPON2 protein was dyed brown particles in cell membranes. 

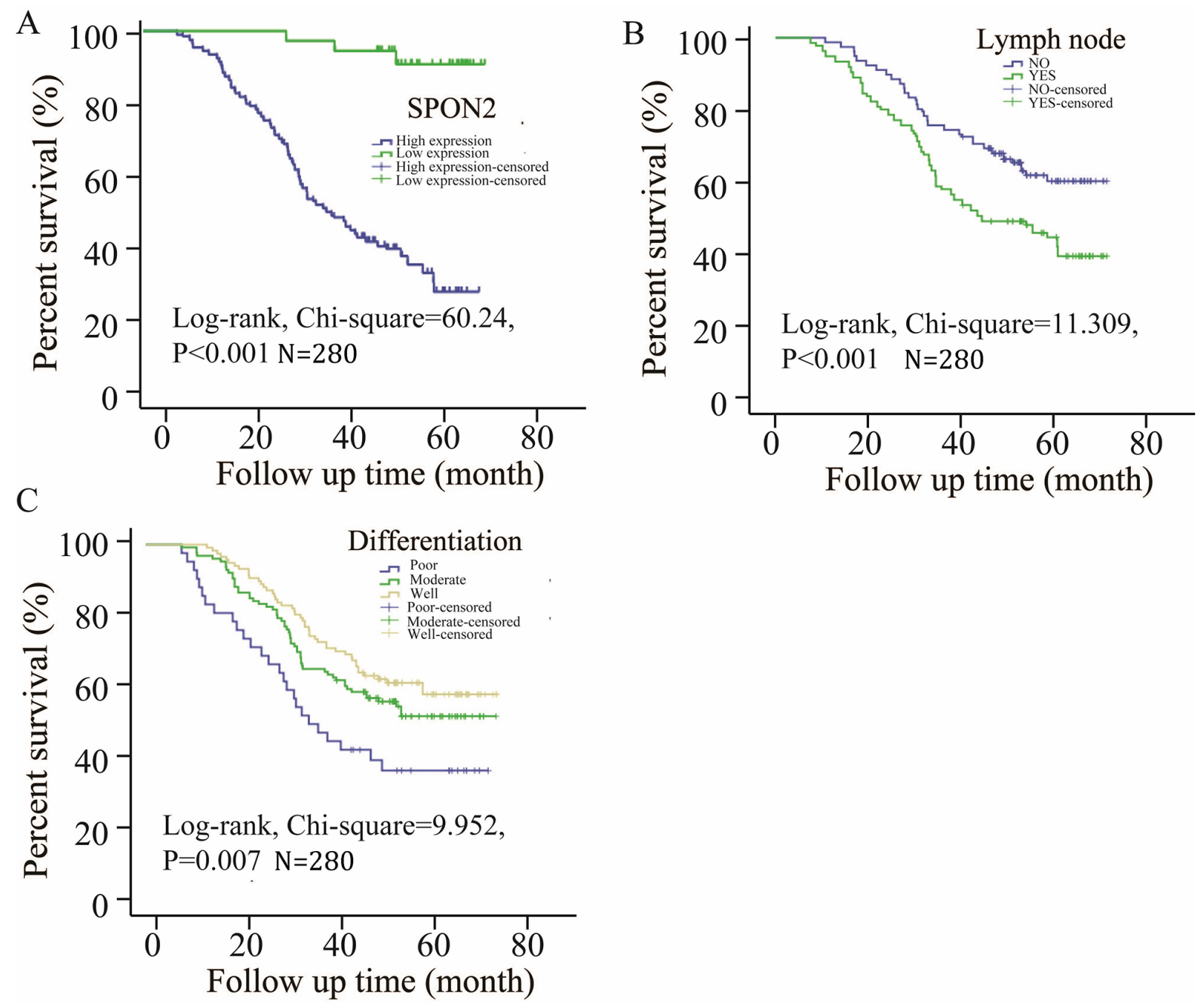

Figure 3: Survival curves of pulmonary ADCs patients by the Kaplan-Meier method and the log-rank test. (A) High expression of SPON2 ADCs patients (blue line) had significantly worse overall survival than low expression of SPON2 ADCs patients (green line); (B) lymph node metastasis (green line) had significantly worse overall survival than no lymph node metastasis (blue line); (C) poor (blue line) or moderate (green line) differentiation ADCs patients had significantly worse overall survival than well differentiation ADCs patients (brown line).
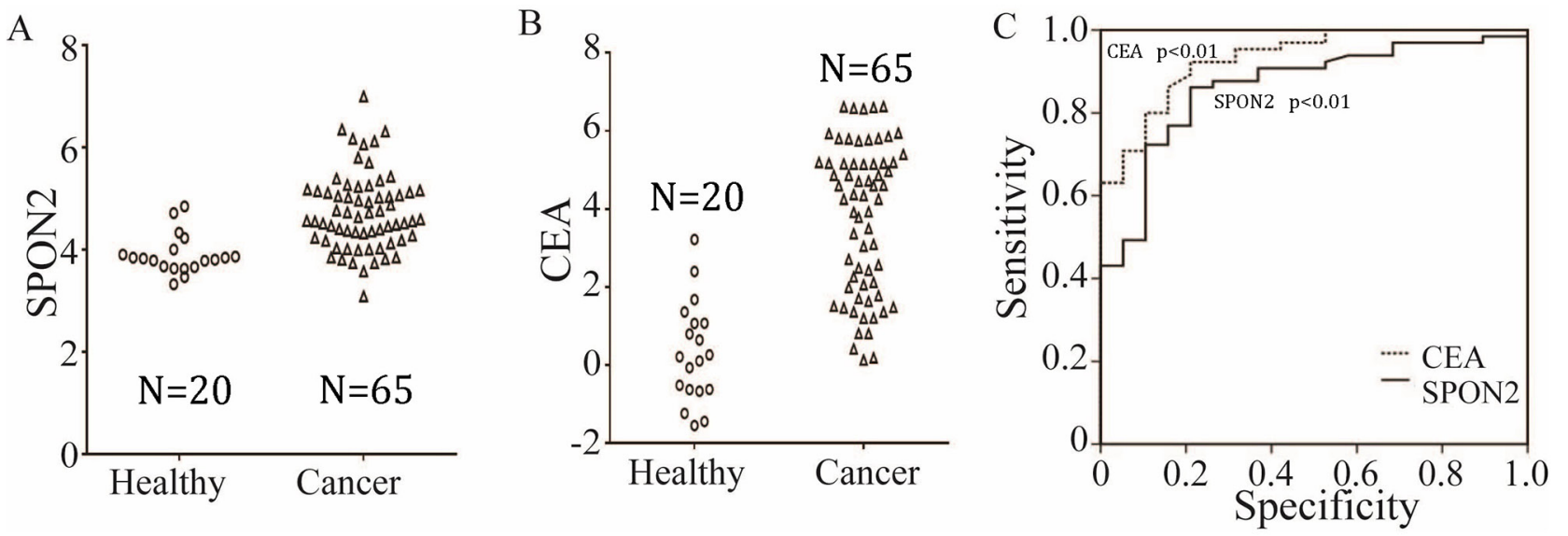

Figure 4: Distribution of serum SPON2 (A) and CEA $(\mathbf{B})$ in healthy individuals $(O)$ and pulmonary ADCs patients $(\Delta)$. The distribution is shown using the standardized values for each marker. (C) ROC curve for all markers using the differentiation of all controls from all pulmonary ADCs cases. The analysis resulted in AUCs of 0.864 (SPON2), 0.932 (CEA). 
survival of colorectal carcinoma and gastric cancer patients $[17,18]$.

SPON2 also plays an important role in some noncancerous diseases, such as type- 2 diabetes and chronic kidney injury disease. SPON2 could also act as a ligand for integrins $[19,20]$. It also has been reported that SPON2 protein can be released from damaged podocyte cells in type 2 diabetic animal models in vitro $[20,21]$. It was recently shown that SPON2 mRNA expression increased in the glomerulus of diabetic mice and that SPON2 is excreted in the urine of patients with type- 2 diabetes and diabetic nephropathy [20-22]. Similarly, there is a linear and significant increase in SPON2 levels in type-2 diabetes patients as the stage of diabetic nephropathy increases, but serum SPON2 levels were not as reliable as that in urine and tissues in the detection of renal damage in diabetic nephropathy [20].

Based on these studies, SPON2 expressed differentially in ovarian, colorectal, prostate, and gastric tumors compared with that in respective normal adjacent tissue; therefore, we concluded that SPON2 protein might be used as a diagnostic biomarker and detected in the patient's blood.

Whether SPON2 overexpression could be detected in pulmonary ADCs patients' serum samples needed to be further investigated. In serum detection assays, SPON2 levels were significantly higher in the serum of pulmonary ADC patients than in that of healthy individuals. Encouragingly, serum SPON2 detection showed high sensitivity and specificity, similar to that in CEA detection. SPON2 protein expression is a potential prognostic biomarker for poor overall survival in pulmonary $\mathrm{ADC}$ patients and might contribute to metastasis of pulmonary ADC. It also has been reported that SPON2 protein expression are significantly higher in prostate cancer patients than in healthy individuals, and, more encouragingly, SPON2 had a stronger diagnostic performance than the percent free-to-total and total prostate-specific antigen (PSA) [8]. It has also been proved that B7-H4, SPON2, and DcR3 are potential biomarkers that might improve early detection of ovarian cancer [6]. Another study showed that SPON2 is a transcriptional target of the metastasis gene MACC1, ectopic SPON2 expression promoted cell motility and proliferation in colorectal cancer cell cultures, metastasis formation was found in mice xenografted with colon cancer, and metastasis-free survival of colorectal cancer patients with low SPON2 expression in vitro $[9,10]$. Therefore, we concluded that SPON2 protein might be used as a diagnostic biomarker and detected in the patient's blood.

The results of our study have provided new insights into the role of SPON2 in the diagnosis and prognosis of ADCs, although several limitations still need to be taken into consideration. First, patients selected for our study were from Jiangsu Province, China. We did not take the regional factor into consideration. Second, the effects of SPON2 expression in pulmonary ADC need to be confirmed on a larger sample of ADC patients in future studies. Finally, the upstream and downstream genes of the signaling pathway in regulation of SPON2 remain unclear, and the mechanism and function of SPON2 in $\mathrm{ADC}$ development and progression need to be further investigated in $\mathrm{ADC}$ cell lines in vitro.

SPON2 might be a potential independent prognostic biomarker for pulmonary ADC, the potential clinical value of detecting SPON2 levels in ADC patients' diagnosis and treatment should be further confirmed in randomized controlled trials and prospective studies.

\section{MATERIALS AND METHODS}

\section{Human tissue samples and patient clinical information}

Human pulmonary ADC cancerous and noncancerous tissue samples were obtained from the Affiliated Hospital of Nantong University, China, with written consent of patients and ethical approval from the Human Research Ethics Committee. In preliminary experiments, 30 pulmonary ADC tissue samples were collected, with 30 normal lung tissue specimens serving as the control Supplementary Table 4. Tissue samples were preserved at $-80^{\circ} \mathrm{C}$. In addition, 280 ADC patients Supplementary Table 1 provided 388 archived formalin-fixed paraffin-embedded tissue blocks.

\section{Quantification of transcription levels by quantitative reverse transcription PCR}

SPON2 mRNA levels were determined by qRT-PCR assay. Relative quantification was administrated using the ${ }^{{ }^{\Delta}} \mathrm{Ct}$ method by first normalizing to housekeeping gene GAPDH mRNA levels, then normalizing to the reference sample. Total RNA was isolated using TRIzol kit (Life Technologies, Shanghai, China) based on the manufacturer's instructions. Each sample was analyzed in triplicate, with GAPDH used for normalization. The ${ }^{\Delta \Delta} \mathrm{Ct}$ method was administrated to calculate the relative amount of SPON2 mRNA in the sample compared with that in the control. The primers involved were as follows: SPON2 forward primer (5'-GCT ACT GTA TGC CAG CCG T-3') and SPON2 reverse primer $\left(5^{\prime}-\mathrm{CTG}\right.$ GAG AAT CAC CGC TTC CT-3'); or SPON2 forward primer (5'-ACT GGC GAT GTG ATC GAG GG-3') and SPON2 reverse primer (5'-CTT TCT TGA ACG GAC TCT GGC-3'); and GAPDH forward primer (5'-CAT GAG AAG TAT GAC AAC AGC CT-3') and GAPDH reverse primer (5'-AGT CCT TCC ACG ATA CCA AAG T-3'). 


\section{Tissue microarray and immunohistochemistry analysis}

The TMA system was constructed based on procedure described as previously [23]. SPON2 protein expression in tissue blocks was determined using TMAIHC. Rabbit polyclonal anti-human SPON2 antibody was used (dilution 1:30; HPA0401710, Atlas, Sweden). The intensity of SPON2 protein staining for each slide was scored and accessed by two different pathologists according to the criterion: 0 and $1+$ (negative, low staining), $2+$ and $3+$ (intense staining), extent of staining was scored from 0 to $100(<50$ and $>50)$. The final quantitation of each staining was obtained by multiplying the two scores. SPON2 IHC data were analyzed by using X-tile software program (The Rimm Lab at Yale University, New Haven, CT, USA; http://www.tissuearray. org/rimmlab) [24].

\section{Human serum samples collection}

Under the condition that all ADC patients and healthy donors were signed with informed consent and enrollment, serum samples from patients with ADC (n $=65)$ and healthy individuals $(\mathrm{n}=20)$ Supplementary Tables 2 and 3 were collected, and the histopathology of ADC were evaluated based on standard pathological guideline. Sixty-five ADC patients had undergone surgery but had received no other therapy, such as chemotherapy, radiotherapy, or targeted therapy. The health of the 20 individuals used as the control was excluded by chest CT, fiber bronchoscope and pathological diagnosis.

\section{ELISA}

SPON2 ELISA Kit (No:DL-SPON2-Hu, Wuxi Donglin Sci \& Tech Development Co. Ltd, Wuxi, China), CEA ELISA Kit (No:ab99992, Abcam, Cambridge, UK). ELISA experiments were administrated based on the manufacturer's protocol. Serum CEA levels were measured referring to this article [25]. Under the condition of $37^{\circ} \mathrm{C}$, prepare samples and standards reagent, add $100 \mu \mathrm{L}$ standard or sample to each well, incubate 2 hours, aspirate and add $100 \mu \mathrm{L}$ prepared Detection Reagent A, incubate 1 hour, then aspirate and wash 3 times, add $100 \mu \mathrm{L}$ prepared Detection Reagent B, incubate 1hour, aspirate and wash 5 times, add $90 \mu \mathrm{L}$ Substrate Solution, incubate 15 minutes, add $50 \mu \mathrm{L}$ Stop Solution, absorbance value was measured at $450 \mathrm{~nm}$. SPON2 concentration in serum was achieved according to standard curves.

\section{Statistical analyses}

SPSS 19.0 (SPSS Inc., Chicago, IL, USA) was used for statistical analyses. The Student t-test was used to calculate the qPCR data when two groups were compared. The Chi-squared test was performed to analyze the correlation between SPON2 expression and clinicopathological characteristics. Univariate and multivariate regression models were administrated to distinguish independent prognostic factors. The Kaplan-Meier method was used to calculate survival curves. ROC curve methods were used to evaluate marker performance both graphically and statistically, [26] and logistic regression analysis was administrated to estimate ideal marker and their weights. The results are shown as the mean $\pm \mathrm{SD}$ of at least three independent experiments. $\mathrm{P}<.05$ was considered statistically significant.

\section{ACKNOWLEDGMENTS}

This study was funded by grants from six talent peaks project in Jiangsu Province, China (No.WSN-059), Scientific research topic of Jiangsu provincial health and Family Planning Commission, China (No.H201626), and Jiangsu young medical talents, Jiangsu, China. Key talents of Medical Science in Jiangsu Province, China(No.2016682).

\section{CONFLICTS OF INTEREST}

The authors have no conflicts of interest to declare.

\section{REFERENCES}

1. Manda R, Kohno T, Matsuno Y, Takenoshita S, Kuwano $\mathrm{H}$, Yokota J. Identification of genes (SPON2 and C20orf2) differentially expressed between cancerous and noncancerous lung cells by mRNA differential display. Genomics. 1999; 61: 5-14.

2. Nurwidya F, Takahashi F, Takahashi K. Gefitinib in the treatment of nonsmall cell lung cancer with activating epidermal growth factor receptor mutation. J Nat Sci Biol Med. 2016; 7: 119-23.

3. Sun S, Schiller JH, Spinola M, Minna JD. New molecularly targeted therapies for lung cancer. J Clin Invest. 2007; 117: 2740-50.

4. Brcic L, Jakopovic M, Misic M, Seiwerth F, Kern I, Smojver-Jezek S, Quehenberger F, Samarzija M, Seiwerth S. Analysis of the frequency of EGFR, KRAS and ALK mutations in patients with lung adenocarcinoma in Croatia. Diagn Pathol. 2016; 11: 90.

5. Clark HF, Gurney AL, Abaya E, Baker K, Baldwin D, Brush J, Chen J, Chow B, Chui C, Crowley C, Currell B, Deuel $\mathrm{B}$, Dowd $\mathrm{P}$, et al. The secreted protein discovery initiative (SPDI), a large-scale effort to identify novel human secreted and transmembrane proteins: a bioinformatics assessment. Genome Res. 2003; 13: 2265-70.

6. Simon I, Liu Y, Krall KL, Urban N, Wolfert RL, Kim NW, Mcintosh MW. Evaluation of the novel serum markers B7-H4, Spondin 2, and DcR3 for diagnosis and early 
detection of ovarian cancer. Gynecol Oncol. 2007; 106: 112-8.

7. Higashijima S, Nose A, Eguchi G, Hotta Y, Okamoto H. Mindin/F-spondin family: novel ECM proteins expressed in the zebrafish embryonic axis. Dev Biol. 1997; 192: 211-27.

8. Lucarelli G, Rutigliano M, Bettocchi C, Palazzo S, Vavallo A, Galleggiante V, Trabucco S, Di Clemente D, Selvaggi FP, Battaglia M, Ditonno P. Spondin-2, a secreted extracellular matrix protein, is a novel diagnostic biomarker for prostate cancer. J Urol. 2013; 190: 2271-7.

9. Chandrasinghe P, Stebbing J, Warusavitarne J. The MACC1-SPON2 axis: a new biomarker and therapeutic target in colorectal cancer. Oncogene. 2017; 36: 1474-5.

10. Schmid F, Wang Q, Huska MR, Andrade-Navarro MA, Lemm M, Fichtner I, Dahlmann M, Kobelt D, Walther W, Smith J, Schlag PM, Stein U. SPON2, a newly identified target gene of MACC1, drives colorectal cancer metastasis in mice and is prognostic for colorectal cancer patient survival. Oncogene. 2016; 35: 5942-52.

11. Arrieta O, Saavedra-Perez D, Kuri R, Aviles-Salas A, Martinez L, Mendoza-Posada D, Castillo P, Astorga A, Guzman E, De la Garza J. Brain metastasis development and poor survival associated with carcinoembryonic antigen (CEA) level in advanced non-small cell lung cancer: a prospective analysis. BMC Cancer. 2009; 9: 119.

12. Arrieta O, Villarreal-Garza C, Martinez-Barrera L, Morales M, Dorantes-Gallareta Y, Pena-Curiel O, Contreras-Reyes S, Macedo-Perez EO, Alatorre-Alexander J. Usefulness of serum carcinoembryonic antigen (CEA) in evaluating response to chemotherapy in patients with advanced non small-cell lung cancer: a prospective cohort study. BMC Cancer. 2013; 13: 254.

13. Dong Y, Zheng X, Yang Z, Sun M, Zhang G, An X, Pan L, Zhang S. Serum carcinoembryonic antigen, neuron-specific enolase as biomarkers for diagnosis of nonsmall cell lung cancer. J Cancer Res Ther. 2016; 12: 34-6.

14. Lee S, Lee CY, Kim DJ, Hong DJ, Lee JG, Chung KY. Pathologic correlation of serum carcinoembryonic antigen and cytokeratin 19 fragment in resected nonsmall cell lung cancer. Korean J Thorac Cardiovasc Surg. 2013; 46: 192-6.

15. Zhu BP, Guo ZQ, Lin L, Liu Q. Serum BSP, PSADT, and Spondin-2 levels in prostate cancer and the diagnostic significance of their ROC curves in bone metastasis. Eur Rev Med Pharmacol Sci. 2017; 21: 61-7.
16. Parra-Cabrera C, Samitier J, Homs-Corbera A. Multiple biomarkers biosensor with just-in-time functionalization: application to prostate cancer detection. Biosens Bioelectron. 2016; 77: 1192-200.

17. Zhang Q, Wang XQ, Wang J, Cui SJ, Lou XM, Yan B, Qiao J, Jiang YH, Zhang LJ, Yang PY, Liu F. Upregulation of spondin-2 predicts poor survival of colorectal carcinoma patients. Oncotarget. 2015; 6: 15095-110. https://doi. org/10.18632/oncotarget.3822.

18. Jin C, Lin JR, Ma L, Song Y, Shi YX, Jiang P, Dong Y, Li XS. Elevated spondin-2 expression correlates with progression and prognosis in gastric cancer. Oncotarget. 2017; 8: 10416-24. https://doi.org/10.18632/ oncotarget.14423.

19. Jia W, Li H, He YW. The extracellular matrix protein mindin serves as an integrin ligand and is critical for inflammatory cell recruitment. Blood. 2005; 106: 3854-9.

20. Kahvecioglu S, Guclu M, Ustundag Y, Gul CB, Dogan I, Dagel T, Esen B, Esen SA, Celik H, Esen I. Evaluation of serum spondin 2 levels in the different stages of type 2 diabetic nephropathy. Nephrology (Carlton). 2015.

21. Murakoshi M, Tanimoto M, Gohda T, Hagiwara S, Takagi M, Horikoshi S, Tomino Y. Mindin: a novel marker for podocyte injury in diabetic nephropathy. Nephrol Dial Transplant. 2011; 26: 2153-60.

22. Murakoshi M, Gohda T, Tanimoto M, Funabiki K, Horikoshi S, Tomino Y. Role of mindin in diabetic nephropathy. Exp Diabetes Res. 2011; 2011: 486305.

23. Yao S, Zhong L, Liu J, Feng J, Bian T, Zhang Q, Chen J, Lv X, Liu Y. Prognostic value of decreased GRK6 expression in lung adenocarcinoma. J Cancer Res Clin Oncol. 2016; 142: 2541-9.

24. Camp RL, Dolled-Filhart M, Rimm DL. X-tile: a new bioinformatics tool for biomarker assessment and outcomebased cut-point optimization. Clin Cancer Res. 2004; 10: 7252-9.

25. Chen S, Dai Y, Zhang X, Jin D, Li X, Zhang Y. Increased miR-449a expression in colorectal carcinoma tissues is inversely correlated with serum carcinoembryonic antigen. Oncol Lett. 2014; 7: 568-72.

26. Mcintosh MW, Drescher C, Karlan B, Scholler N, Urban N, Hellstrom KE, Hellstrom I. Combining CA 125 and SMR serum markers for diagnosis and early detection of ovarian carcinoma. Gynecol Oncol. 2004; 95: 9-15. 